\title{
Creation of the National Atlas of the Arctic
}

\author{
Andrey Tatarenkov \\ The Federal Service for State Registration, Cadastre and Cartography (ROSREESTR), Russian Federation
}

\begin{abstract}
The National Atlas of the Arctic is a fundamental complex cartographic work of informational, scientificapplied nature, containing a set of mutually agreed spatial and temporal information on the physical, geographical and socio-economic features of the Arctic region, intended for use in a wide range of management, economic, scientific, educational, cultural and social activities.
\end{abstract}

Keywords: atlas, Arctic

The Federal Service for State Registration, Cadastre and Cartography developed and published the Arctic region national Atlas in 2017.

The status of the National Atlas of the Arctic assumes its application as an official scientific reference document containing up-to-date information on the natural resource and historical and cultural potential of the territory, technogenic impacts on the natural complexes of the Arctic zone of the Russian Federation and the human habitat.

The National Atlas of the Arctic was created in the form of polygraphic and extended electronic versions.

Technical characteristics of the printed version of the Atlas: Atlas format (cover) 30.0 x $43.0 \mathrm{~cm}$ (book format); number of pages - 496 pages.

The content of the printed version of the National Atlas of the Arctic includes 22 main sections and an index of geographical names.

The main sections of the Atlas contain information on the physical and political geography, socio-economic, natural resource potential of the Arctic zone, the condition and protection of the environment, international cooperation and other topics that comprehensively characterize the Arctic zone of the Russian Federation. Each section has a composition of maps, texts, reference and statistical information and illustrations that characterize the features of this section.

The index of geographical names is created in Russian and contains all geographical names available on the Atlas maps in alphabetical order.

The polygraphic version of the Atlas is printed in 1000 copies.

The extended electronic version of the National Atlas of the Arctic includes the content of the printed version of the Atlas (496 pages), as well as additional thematic maps and text descriptions not included in the polygraphic version (340 pages).

The general structure of the extended electronic version of the National Atlas of the Arctic corresponds to the printed version. Additional thematic maps and text descriptions included in the extended electronic version are available in the relevant sections of the polygraphic version of the Atlas. The numbering of the pages of the National Atlas of the Arctic in the electronic version is through. All thematic maps and text descriptions of the National Atlas of the Arctic are included in the general content (table of contents) of the electronic version of the Atlas, indicating the page number, the name of the map and its scale.

Electronic files of the Atlas are prepared for visual viewing on the screen of the electronic device.

The software tools of the extended electronic version of the Atlas provide operational visualization of the Atlas pages and perform the following functions:

- map search by name and page number;

- output of the required data for printing;

- ability to visualize the specified fragments of cartographic materials (representation on the monitor screen of cartographic information in the form of a map fragment);

- changing the scale of the geospatial information image on the monitor screen (zoom in/out) in interactive mode, or on a given request (setting the appropriate scale);

- distribution on compact discs.

The electronic version for the end user has a single startup file with automatic loading of the main page and a clear transition to the navigation page.

The content of the electronic version of the National Atlas of the Arctic makes it possible to form a single information space of the Russian Federation in its Arctic zone, taking into account natural features, functioning of life support systems and production activities in the natural and climatic conditions of the Arctic region. 